
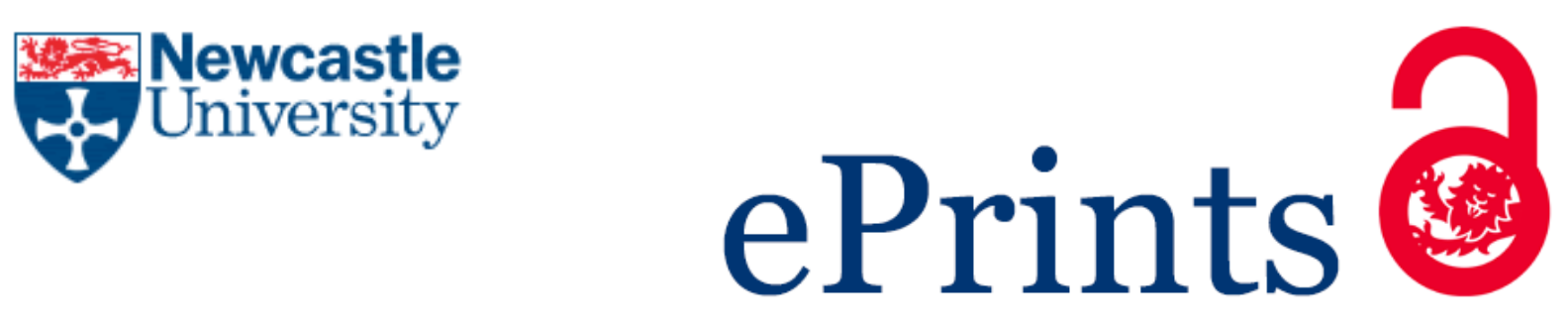

Leelachai M, Benson S, Dow RS. Progressive Collapse of Intact and Damaged Stiffened Panels. In: 5th International Conference on Marine Structures (MARSTRUCT). 2015, Southampton, UK: CRC Press.

Copyright:

(C) The authors, 2015.

Date deposited:

$09 / 09 / 2015$

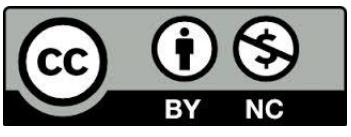

This work is licensed under a Creative Commons Attribution-NonCommercial 3.0 Unported License 


\title{
Progressive collapse of intact and damaged stiffened panels
}

\author{
A. Leelachai, S.D. Benson \& R.S. Dow \\ School of Marine Science and Technology, Newcastle University, UK
}

\begin{abstract}
This paper presents the strength of a series of large scale stiffened steel panels in both intact and damage conditions. The non-linear finite element method is used to simulate damage and calculate the load carrying behavior of the damaged structure. Damage is represented as a circular cut out at different locations on the panel. The extent of the damage is represented as proportion of the panel width and panels with different slenderness ratios are considered with appropriate representation of stresses and initial distortions. The aims of this paper are to produce simplified methods which will enable a better representation of damage in the evaluation of the global strength of the ship structure.
\end{abstract}

\section{INTRODUCTION}

When a ship suffers major damage there is a risk of economic and environmental consequences or even the entire loss of the vessel. To mitigate against these consequences a ship structure should be able to withstand some degree of damage, such as may be caused by collision, grounding or explosion. It is important to evaluate and understand the residual damage strength of a typical vessel to help develop damage tolerant designs and also for use in decision making for improving the recoverability of the ship.

The term 'damage' can be used to describe a diverse range of scenarios. In this paper, extensive rupture damage is idealized such as may be caused by collision with another ship, grounding on a rock or the result of a shock or impact load from weapons attack.

The in-plane compressive strength of a series of large scale stiffened steel panels are evaluated for intact and damage conditions. Damage is represented as a circular cut with a range of sizes and positioned at different locations on the panel. This type of damage representation is similar to that used in the simplified progressive collapse method, where damage is modelled by the removing elements from the otherwise intact structure (Dow 1997). The results are validated through comparison with column collapse curves for intact structure, originally developed by the UK Admiralty Research Establishment (Chalmers 1993) for use in the design of stiffened panels.

The reduction in ultimate strength due to the presence of the damage is presented, and shows that ultimate strength is influenced by a combination of the reduction in cross sectional area and the change in failure mode of the stiffened panel in the damaged zone.

\section{BACKGROUND}

A ship structure is designed to withstand global bending moment acting on the longitudinally continuous structure which comprises the main hull girder. The global bending strength derives from the individual strengths of unstiffened and stiffened plates under in plane axial load. The relatively high slenderness of a hull structure means that the strength is principally a function of the buckling and postbuckling strength of the stiffened panels. The collapse of a stiffened panel is governed by its slenderness and is influenced to some extent by the initial imperfections and residual stresses from the welding process. Smith et al. (1987) studied the behavior of plate elements in between stiffeners under a compressive load and provided data curves of the plate load-shortening behavior that can be used for evaluating hull girder strength.

In addition, a further set of design curves for stiffened panels were published by Smith et al. (1991). These investigated stiffened panels with tee-bar and flat-bar stiffeners under compressive load. The structures were defined with a range of different plate slenderness ratios $(\beta)$ and column slenderness ratio ( $\lambda$ ).. The parameters investigated also included the plate imperfections which were divided in three cases as slight, average and severe imperfections with 3-percentile, 50-percentile and 97-percentile of initial plate displacement $\left(\mathrm{W}_{0}\right)$ and compressive residual stress $\left(\sigma_{\mathrm{RC}}\right)$ respectively. The results of this study 
show that the imperfection becomes more influential for a slender structure that has $\lambda$ over 0.8 .

Damage to a ship could be caused by collision, grounding, explosion and excessive environmental loads. The damage extent and subsequent residual ultimate strength of a ship structure has been the subject of several recent major studies, for example (AbuBakar \& Dow 2013; Marcus 2007; Khedmati 2005). Extensive damage will normally reduce the ultimate strength of the hull girder.

In the simplest sense, a ruptured hole causes a loss in section modulus for a cross section taken through the damage area. More advanced analytical techniques to determine longitudinal ultimate strength, such as the progressive collapse method (Smith 1977) can be used in a similar way to recalculate the ultimate strength of a damaged hull girder (Dow 1997). The damage region is removed from the defined hull girder cross section and the progressive collapse calculations then give an estimate of the residual strength.

Understanding the behavior of damage ship structure will aid in recoverability and decision making in the event of an accident.

\section{CHARACTERISTICS OF STIFFENED PANELS}

\subsection{Panel Parameters}

In this study steel panels with tee-bar stiffeners of dimensions developed by the UK Admiralty Research Establishment are used. Several parameters are used to control the characteristics of the stiffened panel, including:

- Plate slenderness ratio $(\beta)$;

$$
\beta=\frac{b}{t} \sqrt{\frac{\sigma_{y}}{E}}
$$

where $b$ is the plate width, $t$ is the plate thickness, $\sigma_{Y}$ is the material yield stress and $\mathrm{E}$ is the Young's modulus.

- Stiffened panel slenderness $(\lambda)$;

$$
\lambda=\left(\frac{\mathrm{a}}{\pi \mathrm{r}}\right) \sqrt{\frac{\sigma_{\mathrm{y}}}{\mathrm{E}}}
$$

where the radius of gyration is;

$$
r=\sqrt{\frac{I_{x}}{A}}
$$

$I_{x}$ is the second moment of area of the platestiffener cross section:

$$
\begin{aligned}
\mathrm{I}_{\mathrm{x}}= & \mathrm{b}_{\mathrm{p}} \mathrm{t}_{\mathrm{p}}^{3}\left[\mathrm{z}_{0}-\frac{\mathrm{t}_{\mathrm{p}}}{2}\right]^{2}+\mathrm{t}_{\mathrm{w}} \mathrm{h}_{\mathrm{w}}^{3}+\mathrm{t}_{\mathrm{w}} \mathrm{h}_{\mathrm{w}}\left[\mathrm{z}_{0}-\mathrm{t}_{\mathrm{p}}-\frac{\mathrm{h}_{\mathrm{w}}}{2}\right]^{2} \\
& +\mathrm{b}_{\mathrm{f}} \mathrm{t}_{\mathrm{f}}^{3}+\mathrm{b}_{\mathrm{f}} \mathrm{t}_{\mathrm{f}}\left[\mathrm{z}_{0}-\mathrm{t}_{\mathrm{p}}-\mathrm{h}_{\mathrm{w}}-\frac{\mathrm{t}_{\mathrm{f}}}{2}\right]^{3}
\end{aligned}
$$

- Stiffened area ratio

$$
\frac{A_{s}}{A}=\frac{\text { The cross section area of the stiffeners }}{\text { Total cross section area of the whole structure }}
$$

For this study the stiffened panels are assumed to be constructed from a mild steel material which has yield stress $\left(\sigma_{\mathrm{y}}\right)$ of $245 \mathrm{MPa}$ and Young's modulus of $207 \mathrm{GPa}$. An elastic perfectly plastic material model is assumed.

Furthermore, the analysis uses the average residual stress magnitude equivalent to previous studies (Chalmers 1993; Smith et al. 1991). The scope of analysis for this paper has been provided in Table 1.

Table 1.Panel Parameters

\begin{tabular}{llc}
\hline Parameter & Intact & Damaged \\
\hline Material Property & & \\
Yield stress $\left(\sigma_{\mathrm{y}}\right)$ & $245 \mathrm{MPa}$ & $245 \mathrm{MPa}$ \\
Young's modulus $(\mathrm{E})$ & $207 \mathrm{GPa}$. & $207 \mathrm{GPa}$ \\
Structure Parameters & & \\
Plate slenderness ratio $(\beta)$ & $1 \leq \beta \leq 4$ & $\beta=2$ \\
Column slenderness ratio $(\lambda)$ & $0.2 \leq \lambda \leq 1.0$ & $\lambda=0.3,0.5$ \\
Stiffener area ratio $\left(\mathrm{A}_{\mathrm{s}} / \mathrm{A}\right)$ & $0.1 \leq \mathrm{A}_{\mathrm{s}} / \mathrm{A} \leq 0.4$ & $\mathrm{~A}_{\mathrm{s}} / \mathrm{A}=0.2$ \\
Stiffener shape & Admiralty long-stalk tee bar \\
\hline
\end{tabular}

A study has been carried out to investigate the effect of $A_{s} / A$ and a standard value of $A_{s} / A=0.2$ has been selected.

\subsection{Boundary conditions}

The boundary conditions of the stiffened panel are set to ensure buckling nucleates in the central bays by using fixed supports on the transverse ends. A simple support condition is assumed on the longitudinal edges. Transversely, the model has been fixed at one end, which does not allow movement or rotation in any direction, except in x-direction to allow the long edges of the panel to pull-in. On the loaded end a compressive displacement is applied to the structure in the z-direction whilst other constraints are fixed as for the opposite edge. Load is displacement controlled. Longitudinally, both edges of the stiffened panel are constrained in y-direction but are free in the z-direction to enable compressive displacement throughout the panel length. One edge is constrained in $\mathrm{x}$-direction whilst the other is free to pull in but constrained to remain straight.

Figure 1 demonstrates the overall boundary condition of structure. 


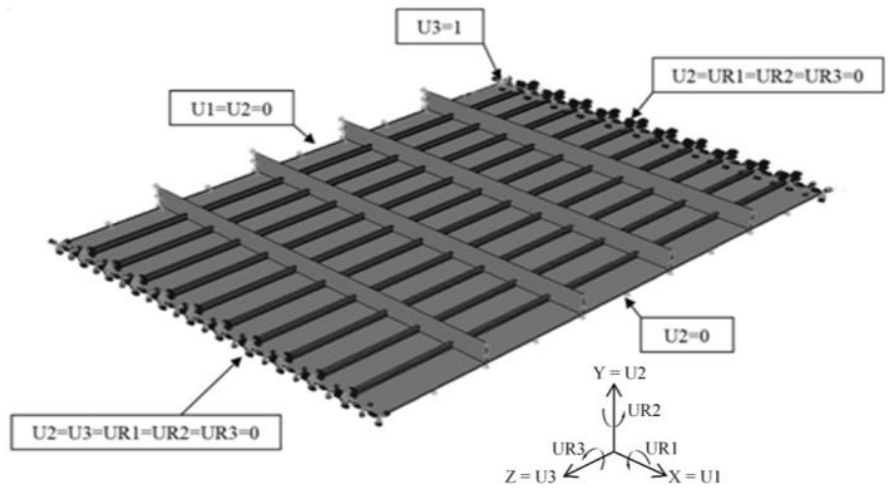

Figure 1. Boundary conditions of stiffened panel.

\subsection{Initial conditions}

The imperfection is a major parameter that can generate a premature collapse for both the intact and damaged structure. Initial deformation can be caused during construction (particularly through weld wrap up). Additional imperfections can then be caused by lateral loads during service. In this paper we focus on the "average" level of plating distortion and residual stress from previous study (Smith et al. 1991). The parameters are presented in Table 2.

Table 2.Initial conditions

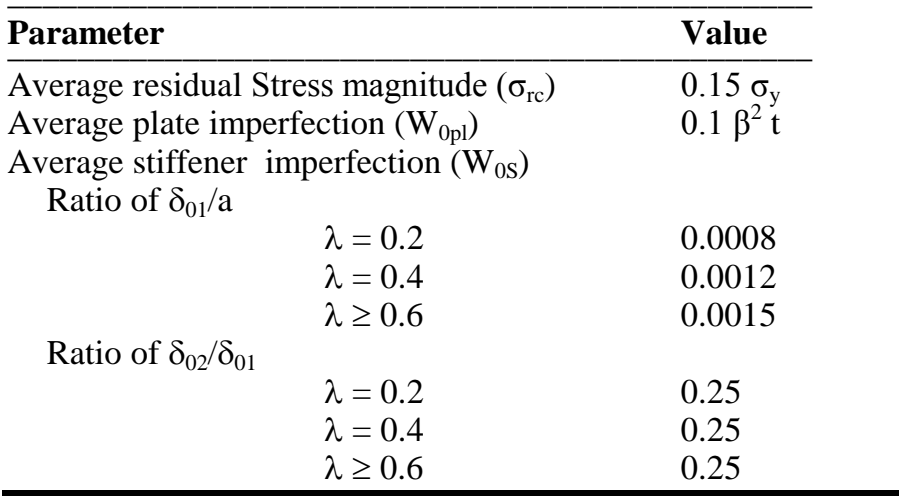

The width of the plate is " $b$ " and length "a" as shown in Figure 2.

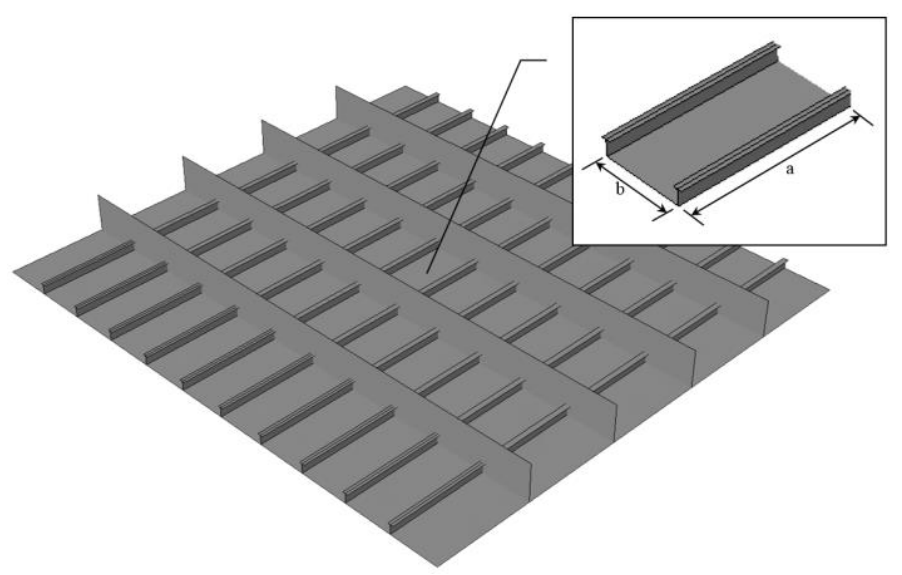

Figure 2. Reference of plate element.

The rectangular plate imperfection is a combination of two different deformations; the width of the plate $b$ has a single half-wave. The deformation of the plate width, with a single half-wave, is shown in Figure 3.

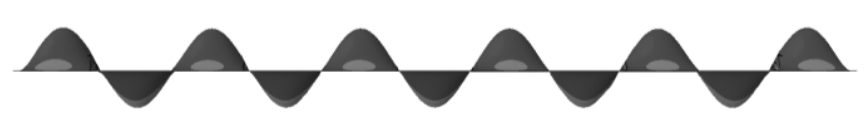

Figure 3. Imperfection on the width edge (b).

While the length a has a combination of $80 \%$ single half-wave and $20 \%$ five half-wave (see Figure 4). This enables a better representation of the eventual buckling nucleation in the finite element analysis. The imperfection formula of five half-wave is below:

$$
W_{0}=\overline{W_{0}} \sin \frac{5 \pi x}{a} \sin \frac{\pi y}{b}
$$

Steel plate, moreover, includes an effect from welding that produces more deformation into the plate as demonstrate in Figure 5. In this study, the stiffeners have the average imperfection as in Table 2.

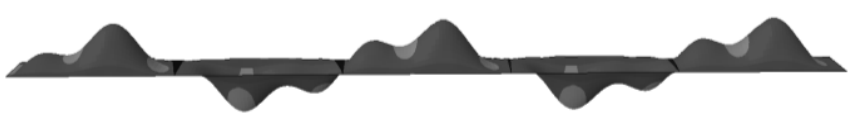

Figure 4. Imperfection on the length edge (a). Because of the welding along the stiffener.

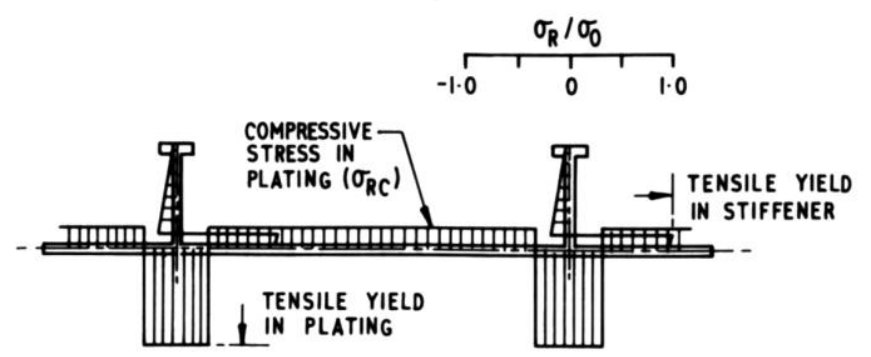

Figure 5. Imperfection on the width edge (b). (Chalmers. 1993)

\section{FINITE ELEMENT METHODS}

\subsection{Non-linear finite element methods}

A static non-linear finite element method utilizing ABAQUS (2012) is used for the analysis. The Risk arc length procedure coupled with Newton-Raphson is used to solve the static non-linear problem. This is required because of the high level of nonlinearity in the buckling response of the stiffened panel when loaded in in-plane compression.

\subsection{Finite element program}

The general purpose nonlinear capability of ABAQUS has been used to carry out implicit static analysis. The models have been created with a shell 
element type S4R, that are four node general purpose shell elements valid for both thick and thin shell problems. Initial imperfections are seeded into the mesh using direct translation of the nodes. Weld induced residual stresses are represented by applying initial stress conditions in pre-defined tensile and compressive zones on the panel (with distribution as shown in Figure 5).

\subsection{Analysis Procedure}

In the analysis, the residual stress is applied into the stiffened panel as a pre-load. To ensure initial equilibrium before applying load into the structure a relax step has been created. This allows the structure to self-equilibrate before applying compression load.

The compression load has been applied to the structure by specifying increased displacement at one end of the structure. A reference point (RF1) is created at the end of the structure. This reference point tied all nodes at the end of the structure together. This ensures displacement is controlled across the entire panel width and that the load is easily output from the analysis results.

\subsection{Mesh}

In the ABAQUS program, mesh size should be selected appropriately for the analysis of the model by balancing between accuracy and reasonable analysis time. In this study, a characteristic element length of $25 \mathrm{~mm}$ was found appropriate through a convergence study. The mesh density is demonstrated in Figure 6, which shows that longitudinals are modelled with 4 elements in the web height and 2 elements across the flange This is consistent with previous mesh densities used for these types of analyses (Benson et al. 2013).

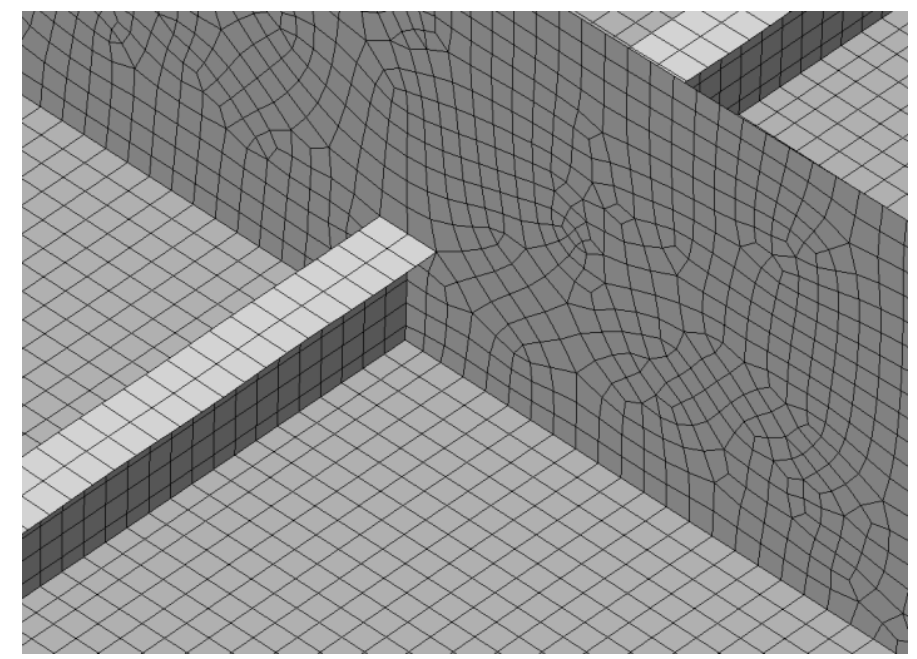

Figure 6.Design mesh in ABAQUS program.

\subsection{Intact structure}

In this paper we show results for intact panels with the plate slenderness ratio $(\beta)$ of 2.0 ; column slenderness $(\lambda)$ of 0.3 ; stiffener area ratio of 0.2 ; and us- ing a 5 inches long stalk tee stiffener, which is described in Table 3 and Figure 7. Transverse frames were sized to ensure interframe collapse of the panel in the intact condition. A full range of plate and column slenderness parameters have been tested and will be reported in a future publication.

Table 3. Dimension of 5 inches long stalk tee.

\begin{tabular}{ll}
\hline Parameter & Value \\
\hline $\mathrm{h}_{\mathrm{w}}(\mathrm{mm})$ & 127.0 \\
$\mathrm{t}_{\mathrm{w}}(\mathrm{mm})$ & 6.65 \\
$\mathrm{~b}_{\mathrm{f}}(\mathrm{mm})$ & 63.5 \\
$\mathrm{t}_{\mathrm{f}}(\mathrm{mm})$ & 13.4 \\
Section area; $\mathrm{A}_{\mathrm{S}}\left(\mathrm{mm}^{2}\right)$ & 1606.3 \\
Second moment area; $\mathrm{I}_{\mathrm{X}}\left(\mathrm{mm}^{4}\right)$ & 2438715 \\
\hline
\end{tabular}

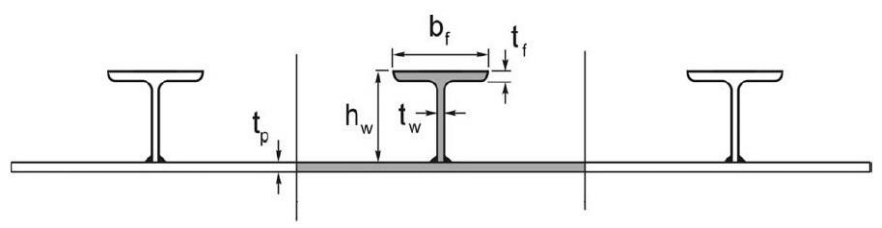

Figure 7.Dimension of long stalk tee.

The transverse frames were sized to ensure interframe buckling. The transverse frame size is $450 \mathrm{x}$ $10 \mathrm{~mm}$.

\subsection{Damage structure}

Damage is represented by a circular hole. The size of the damage hole depends on the ratio between diameter of hole (D) and width (W) of the structure (Figure 8). The characteristics of the damage panels shown in this paper are the same as those for the intact condition. Analyses are completed for damage cases with the ratio (D/W) from 0.0 to 0.8 (see Table 4). Further work is ongoing to extend the parametric study to different panel slenderness ratios.

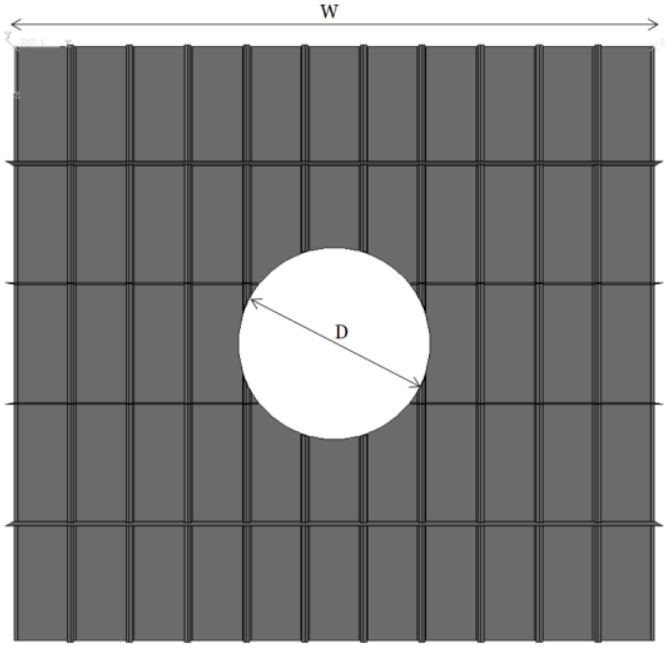

Figure 8.Damage clear cut hole diagram. 
Table 4.Size of damage clear cut hole.

\begin{tabular}{ccc}
\hline Hole ratio $(\mathbf{D} / \mathbf{W})$ & Hole diameter & $(\mathbf{m m})$. \\
\hline 0.00 & 0.0 & \\
0.05 & 320.5 & \\
0.10 & 641.0 & \\
0.15 & 961.5 & \\
0.20 & 1282.0 & \\
0.25 & 1602.5 & \\
0.30 & 1923.0 & \\
0.35 & 2243.5 & \\
0.40 & 2564.0 & \\
0.45 & 2884.5 & \\
0.50 & 3205.0 & \\
0.55 & 3525.5 & \\
0.60 & 3846.0 & \\
0.65 & 4166.5 & \\
0.70 & 4487.0 & \\
0.75 & 4807.5 & \\
0.80 & 5128.0 & \\
\hline
\end{tabular}

\section{RESULTS}

\subsection{Intact structure}

Care was taken to ensure the intact panels buckle with an interframe mode. This was achieved by sizing the transverse frames appropriately and checking the results of the finite element analyses both with the load shortening curves and the visualized buckling pattern. An example is shown in Figures 9. The analysis carries on with the standard value $\left(\mathrm{A}_{\mathrm{s}} / \mathrm{A}\right)$ of 0.2 with the 5 inch long stalk tee. The stress-strain load shortening curve of the intact panel shows three main areas: pre-collapse, collapse and post-collapse.

The buckling is shown to nucleate into the central bay (Figure 10-12). Comparisons of these results with the damaged structures are shown in the next section.

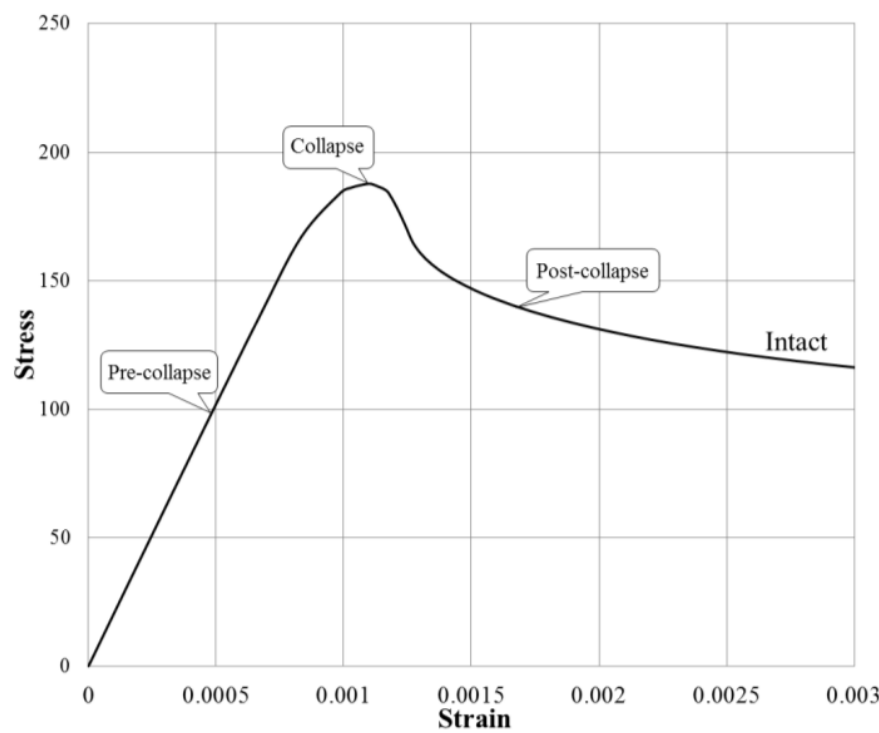

Figure 9.Stress - Strain curve for stiffened panel with plate slenderness ratio $(\beta)$ of 2.0 , Stiffened panel slenderness $(\lambda)$ of $0.3,5$ inches long stalk tee with stiffener area ratio of 0.2

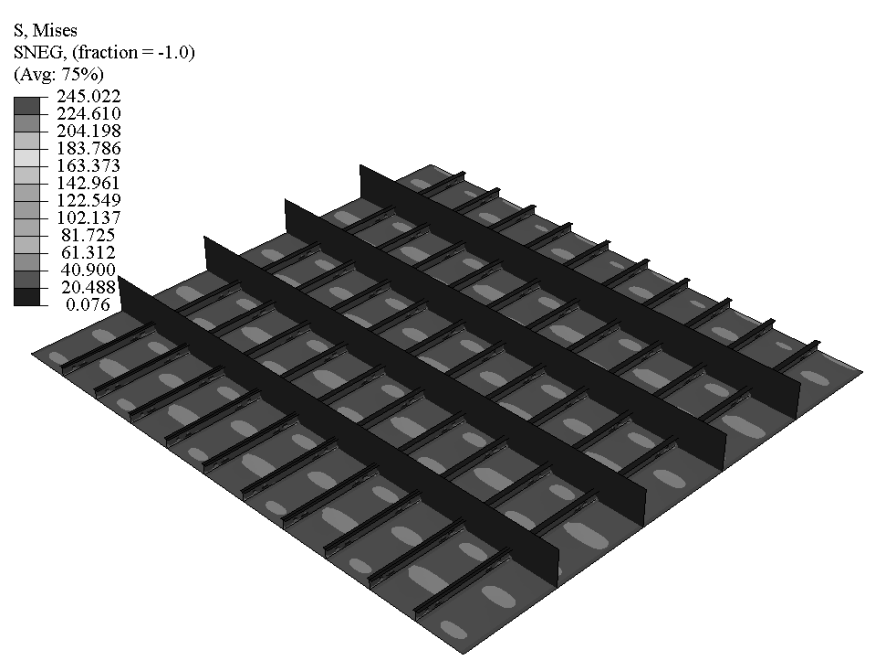

Figure 10.Pre-collapse model for stiffened panel with plate slenderness ratio $(\beta)$ of 2.0 , Stiffened panel slenderness $(\lambda)$ of $0.3,5$ inches long stalk tee with stiffener area ratio of 0.2 .

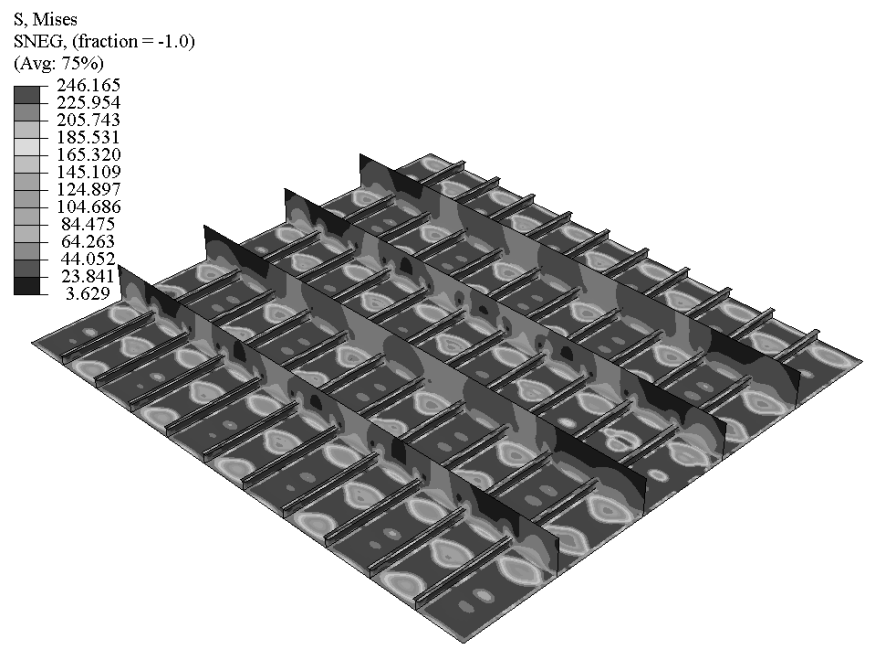

Figure 11.Collapse model for stiffened panel with plate slenderness ratio $(\beta)$ of 2.0 , Stiffened panel slenderness $(\lambda)$ of 0.3 , 5 inches long stalk tee with stiffener area ratio of 0.2 .

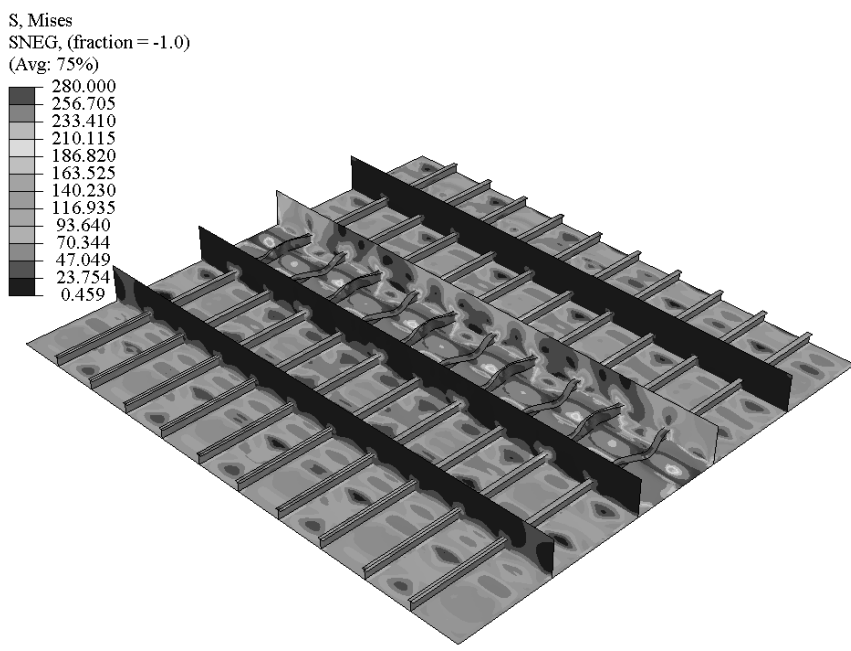

Figure 12.Post-collapse model for stiffened panel with plate slenderness ratio $(\beta)$ of 2.0 , Stiffened panel slenderness $(\lambda)$ of $0.3,5$ inches long stalk tee with stiffener area ratio of 0.2 . 


\subsection{Damage structure}

As described previously, the damaged structures are modelled with a circular cut hole in the stiffened panel. Figure 13 shows one of the analyses which has a plate slenderness ratio $(\beta)$ of 2.0 ; Stiffened panel slenderness $(\lambda)$ of 0.3 ; the standard value $\left(\mathrm{A}_{\mathrm{s}} / \mathrm{A}\right)$ of 0.2 and Damage circular hole ratio $(\mathrm{D} / \mathrm{W})$ of 0.3 .

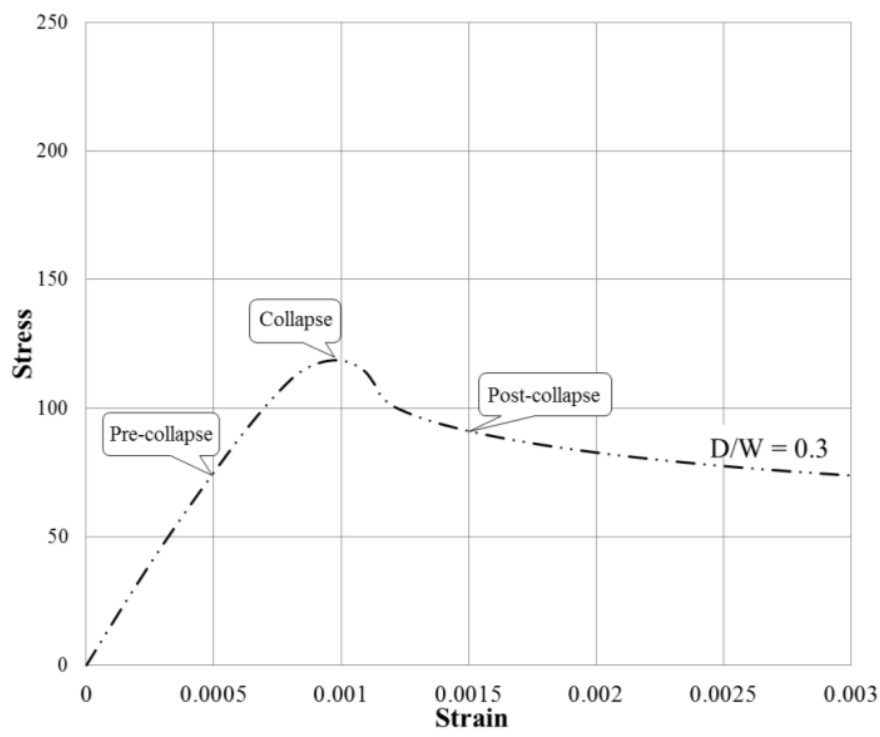

Figure 13.Stress-Strain curve for damaged structure with plate slenderness ratio $(\beta)$ of 2.0 , Stiffened panel slenderness $(\lambda)$ of $0.3,5$ inches long stalk tee, Damage circular hole ratio $(\mathrm{D} / \mathrm{W})$ of 0.3 with stiffener area ratio of 0.2

The result shows the collapse still occurs interframe in a similar way to the intact model. In addition, the cut hole reduces the section area of the stiffened panel and decrease strength of the structure. Figure 17 demonstrates the stress and strain curve of the stiffened panel with different sizes of cut out. Progressively increasing the size of the cut out causes a gradual drop of strength. In addition the stiffness of the panel in the pre-collapse region reduces progressively. The shape of the load shortening curve remains relatively consistent throughout.

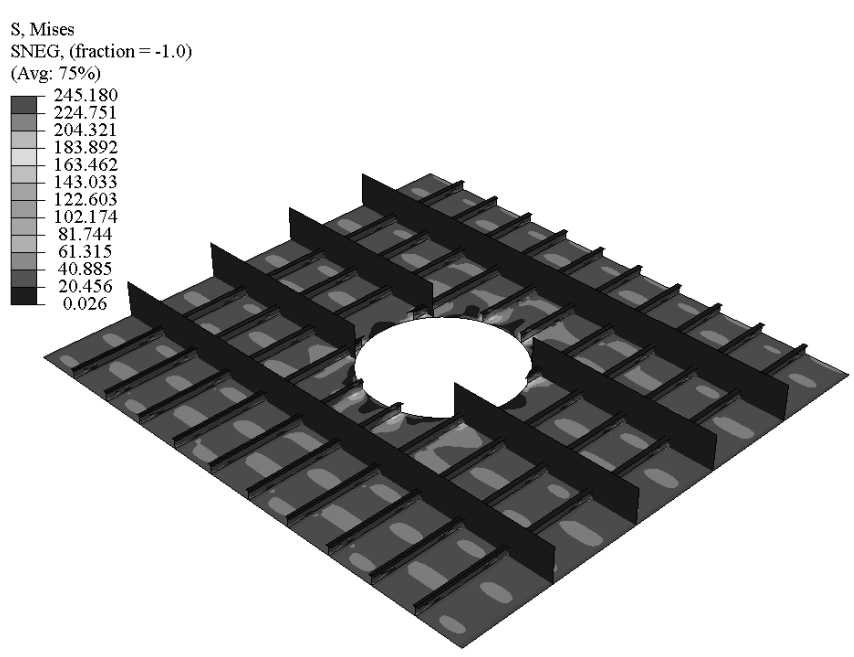

Figure 14.Pre-collapse model for damaged structure with plate slenderness ratio $(\beta)$ of 2.0 , Stiffened panel slenderness $(\lambda)$ of $0.3,5$ inches long stalk tee, Damage circular hole ratio (D/W) of 0.3 with stiffener area ratio of 0.2

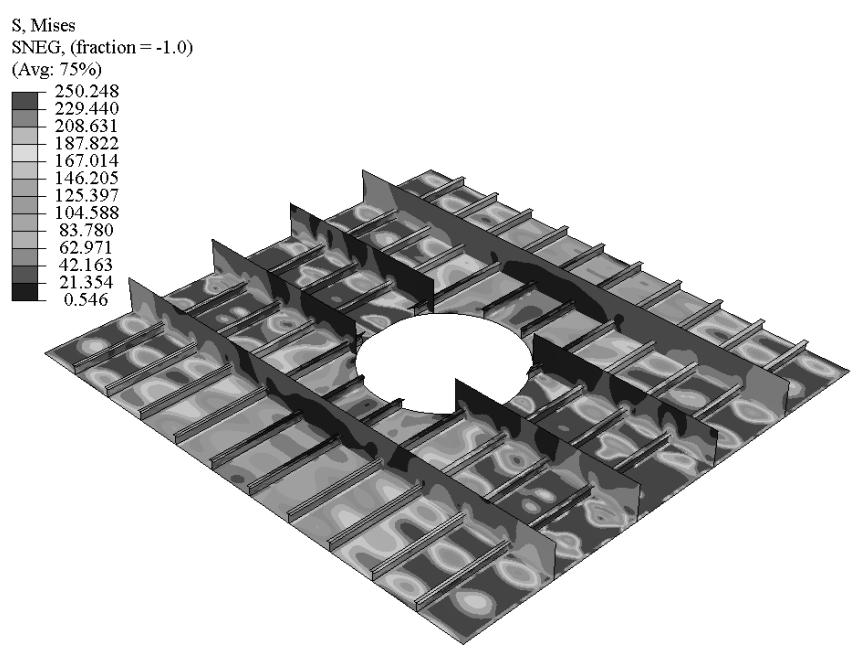

Figure 15.Collapse model for damaged structure with plate slenderness ratio $(\beta)$ of 2.0, Stiffened panel slenderness $(\lambda)$ of $0.3,5$ inches long stalk tee, Damage circular hole ratio $(\mathrm{D} / \mathrm{W})$ of 0.3 with stiffener area ratio of 0.2

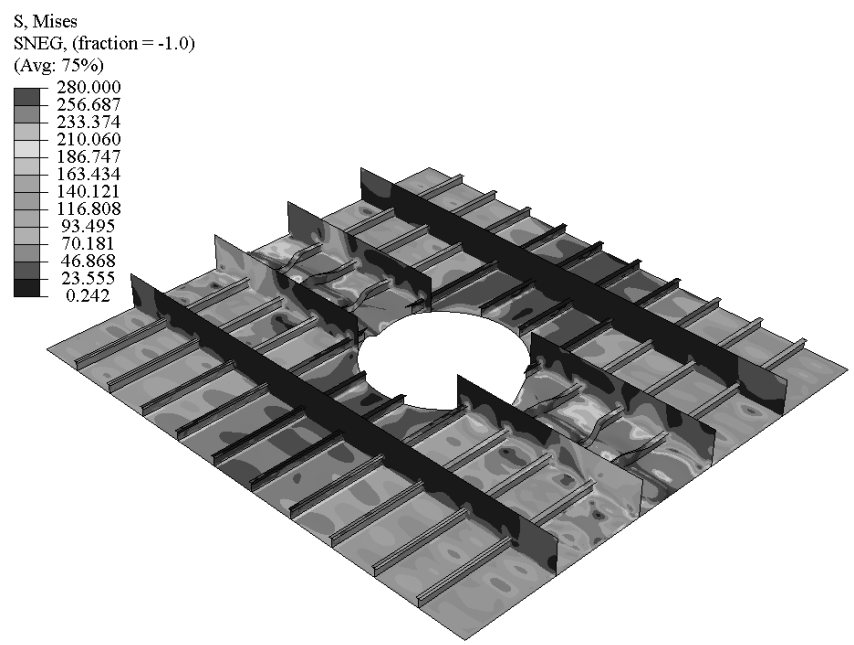

Figure 16.Post-collapse model for damaged structure with plate slenderness ratio $(\beta)$ of 2.0 , Stiffened panel slenderness $(\lambda)$ of $0.3,5$ inches long stalk tee, Damage circular hole ratio (D/W) of 0.3 with stiffener area ratio of 0.2 


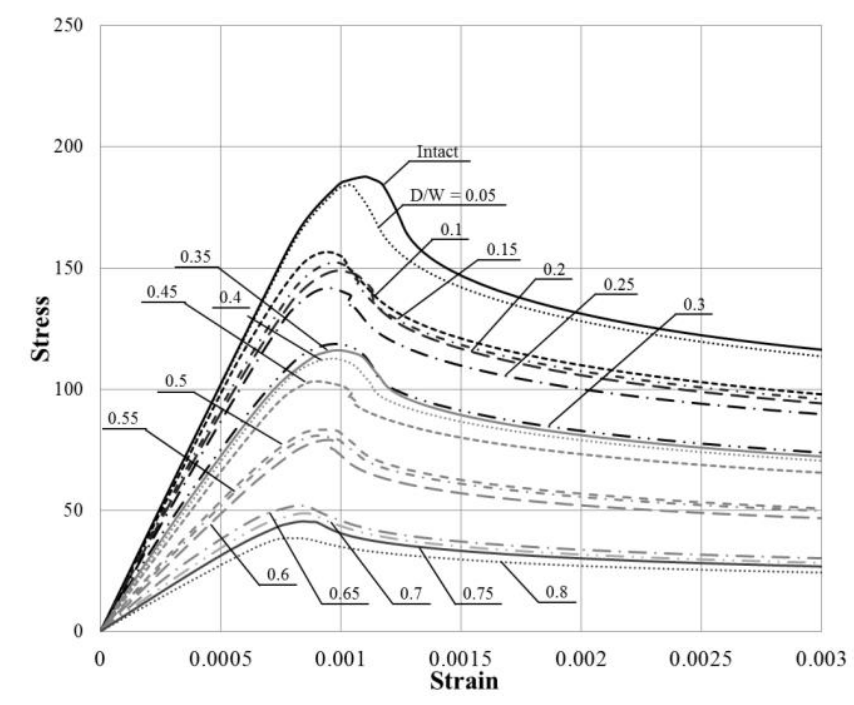

Figure 17.Stress-strain curve of damage circular cut hole $\left(\mathrm{B}=2.0, \lambda=0.3, \mathrm{~A}_{\mathrm{s}} / \mathrm{A}=0.2\right)$.

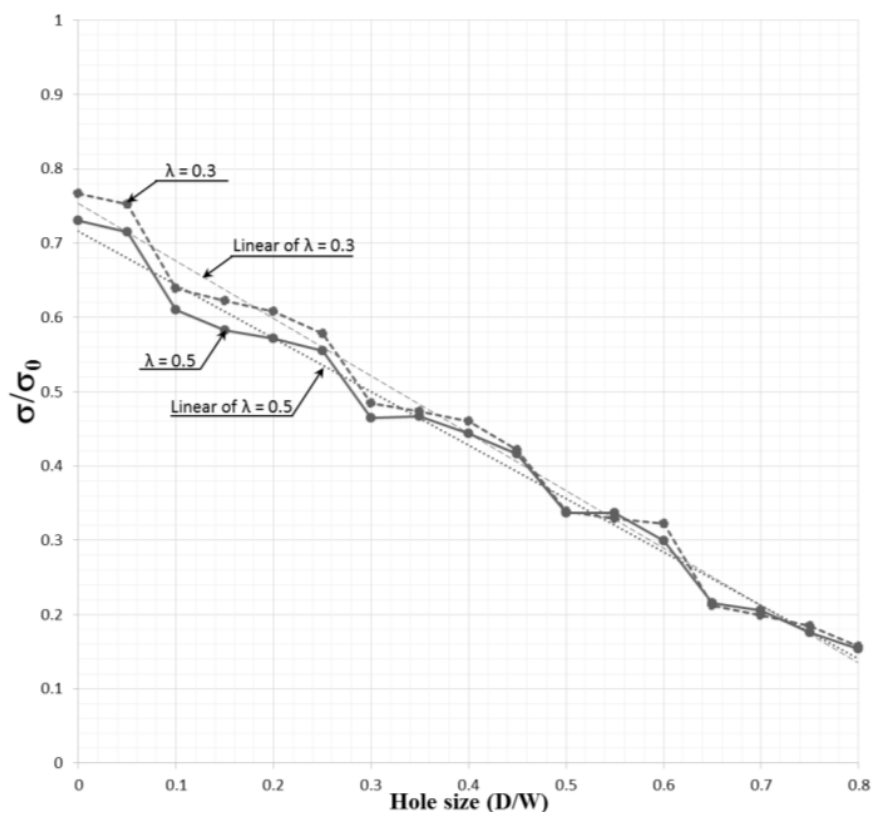

Figure 18.Stress - circular hole size curve of stiffened panel $(\beta)$ of 2.0 and 5 inches long stalk tee.

Figure 18 shows a comparison of the ultimate strengths predicted for panels with progressively increasing cut out hole size. Both stiffened panel slenderness $(\lambda)$ of 0.3 and 0.5 are shown. Only one value of $\beta=0.2$ is presented here.

The pattern of ultimate strength reduction in Figure 18 shows a clear and understandable pattern. The strength is relatively unaffected as the hole size increases across an unstiffened plate, indicated by the flatter regions of the curve. Once the hole cuts through a longitudinal stiffener the strength takes a sharp drop. In this instance, the hole cuts through two stiffeners at a time because it is located centrally on the panel. The ultimate strength reduction is therefore consistent with the loss of cross section area in the damaged area of the panel.

There is little indication of a different failure pattern or an influence on the ultimate strength when the hole cuts through the transverse frames. Howev- er, this may not be the case for different stiffened panel arrangements and is currently being investigated by the authors.

Furthermore, a study looking at different $\beta$ values could affect the buckling behavior of the structure and lead to revised insights on how a stiffened panel can respond to damage.

\section{CONCLUSIONS}

For an intact stiffened panel the effect of imperfection and residual stress are important factors affecting the ultimate strength of the panel under in-plane compression. With the inclusion of damage, represented as a cut out, it is shown that the ultimate strength reduction is consistent with the loss of cross section area in the damaged area of the panel. The residual stress and imperfections are still important to model because the cut out is inserted in otherwise unaffected surrounding structure. The cut out area can reduce stress with a step function as shown on the graph in Figure 18. Strength drops sharply when the stiffeners are cut through and then plateaus for further increases in hole size.

This work is currently continuing to investigate panels with damage represented by circular cut out and been extended to investigate the following parameters $\beta$ from 1.0 to 4.0 and $\lambda$ from 0.2 to 1.0 .

The investigation of damaged strength is being extended to investigate the effects of the actual damage mechanism a residual strength. More realistic representations of damage will be considered to model accidents such as collision and grounding.

\section{ACKNOWLEDGEMENTS}

This study was performed under an Office of Naval Research grant. The authors would like to thank ONR for their continuing support of this work.

\section{REFERENCES}

ABAQUS. 2012, ABAQUS Analysis User's Manual, Version 6.12, Dassault Systèmes Simulia Corporation.

AbuBakar A. and Dow R.S. 2013, "Simulation of ship grounding damage using the finite element method", International Journal of Solids and Structures 50, p.623 - 636

Benson S., Leelachai A. and Dow R.S. 2013 "Ultimate Strength of stiffened panels with circular cut-outs under in plane compression". 12th International Conference on Fast Sea Transportation, Amsterdam, Netherlands.

Chalmers D.W. 1993, "Design of Ships' Structures.", London: HMSO. 
Dow R.S. 1997, "Structural redundancy and damage tolerance in relation to ultimate ship hull strength", Advances in Marine Structures 3.

Khedmati M.R. 2005, "Simulation of Average Stress-

Average Strain Relationship of Shi Unstiffened/ Stiffened Plates Subject to in-plane Compression", Scientia Iranica, Vol. 12, No.4, p.359- 367

Marcus B. 2007, "Introducing Damage Structural As sessment to Onboard Decision Support Tools", COMPIT'07, p.386 - 399

Smith C. S. 1977. Influence of local compressive failure on ultimate longitudinal strength of a ship's hull. PRADS 1977: 73-79.

Smith C.S., Davidson P.C. et al. 1987, "Strength and stiffness of ships' plating under in-plane compression and tension", Transactions of Royal Institution of Naval Architects, p.277-296

Smith C.S., Anderson J.C. et al. 1991, "Strength of stiffened plating under combined compression and lateral pressure", Transactions of The Royal Institution of Naval Architects, p.131-147 